\title{
REDUÇÃO DOS DESVIOS DE PLACAS POR DESOBSTRUÇÃO DOS VEIOS NA MCC 2*
}

\author{
Camila Lourenço Soares ${ }^{1}$ \\ Cristóvão Ferreira ${ }^{2}$ \\ Ederson de Oliveira ${ }^{3}$ \\ Robson Luiz da Silva Nascimento ${ }^{4}$
}

\section{Resumo}

A produção de aço no mundo está a cada dia mais competitivo, com isso as indústrias siderúrgicas tem desenvolvidos projetos com foco na melhoria da qualidade dos aços e na redução dos custos dos processos de fabricação. Este trabalho descreve as melhorias realizadas no processo de lingotamento contínuo, com foco na redução do desvio de placas por desobstrução dos veios da MCC 2. Esta melhoria consistiu na modificação do sistema de controle e injeção de argônio dos veios durante o lingotamento. A implementação dessas ações propiciou um melhor controle na injeção de argônio no sistema de válvula gaveta, reduzindo significativamente as obstruções do veio por deposição de alumina. Hoje, com os resultados alcançados na MCC 2 perduramos entre as melhores práticas nacionais. O trabalho foi realizado sem investimento contribuindo com a redução do custo de transformação do aço em placa.

Palavras-chave: Obstrução; Alumina; Desclassificação de placas.

\section{REDUCTION THE DOWNGRADE OF SLABS FOR CLOGGING IN MACHINE CASTING CONTINUOUS 2}

\section{Abstract}

The steelmaking in the world is increasingly competitive, with that the steel industry has developed projects focused on improving the quality of steels and reducing the costs of manufacturing processes. This paper describes the improvements made in the continuous casting process, focusing on reducing the downgrade slabs for clogging in CCM 2. This improvement was the modification argon control and injection system of strands during casting. The implementation of this action led to better control the argon injection into the flow control system, radically reducing the clogging of the strands by deposition of alumina. Today, with the results achieved at CCM 2 have become national references. The work was carried out without investment contributing to the decline in the steel processing cost slab

Keywords: Clogging; Alumina; Downgrade.

1 Engenharia Metalúrgia, MSc., Engenheira de Desenvolvimento Lingotamento Contínuo, GMP, Companhia Siderúrgica Nacional, Volta Redonda, Rio de Janeiro, Brasil.

2 Ciências Contábeis, Líder de Lingotamento Contínuo, GLA, Companhia Siderúrgica Nacional, Volta Redonda, Rio de Janeiro, Brasil.

3 Eletrônica, Técnico em Eletrônica, Inspetor Manutenção, GMA, Companhia Siderúrgica Nacional, Volta Redonda, Rio de Janeiro, Brasil.

4 Engenharia Metalúrgica, Engenheiro, Engenheiro Especialista Lingotamento Continuo, GLA, Companhia Siderúrgica Nacional, Volta Redonda, Rio de Janeiro, Brasil. 


\section{INTRODUÇÃO}

O lingotamento continuo nas máquinas 2 e 3 , da CSN, permite a produção de sequencias de 12 corridas, proporcionando produtividade e qualidade a custo baixo. Entretanto, existem fenômenos que impedem a continuidade do processo.

Dentre os fenômenos, a obstrução reduz e/ou interrompe a vazão de aço do distribuidor para o molde, impactando na perda de produtividade, aumento do custo e redução na qualidade interna das placas de aço.

Existem quatro diferentes mecanismos de obstrução de tubo submerso, sendo que na prática evidenciamos a combinação de dois ou mais mecanismos. Esses mecanismos são provenientes da solidificação do aço, desoxidação, produtos de reação e óxidos complexos [1].

Diante dos mecanismos térmicos e químicos que promovem a obstrução dos veios, os térmicos são causados devido ao baixo superaquecimento e ou elevada extração de calor favorecendo a solidificação prematura do aço. Para minimizar esta ocorrência deve-se ter um controle de temperatura confiável bem como uma eficiente adição de material de cobertura evitando a perda térmica.

As causas das obstruções por mecanismos químicos estão relacionadas com limpidez do aço e as reações decorrentes da interação do aço com o material refratário. São utilizados vários métodos como injeção de silicato de cálcio, injeção de argônio, controle de escória no distribuidor e dos compostos e geometria dos materiais refratários $[2,3]$.

Uma vez identificada à obstrução durante o lingotamento, o método operacional de limpeza e desobstrução do poço com vara é executado com objetivo de remover fisicamente os óxidos aderidos, que impedem o fluxo de aço distribuidor/molde. Estes são absorvidos para o interior do molde, podendo provocar esfoliação no produto acabado.

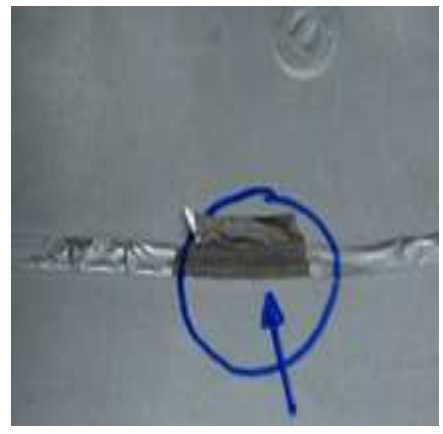

(a)

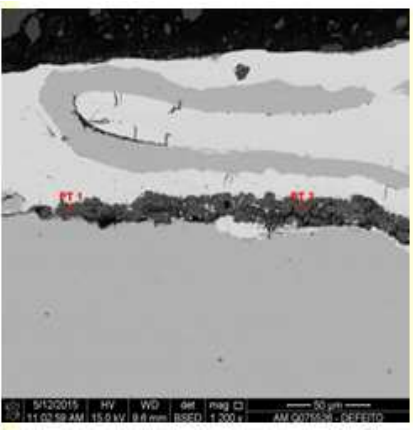

(b)

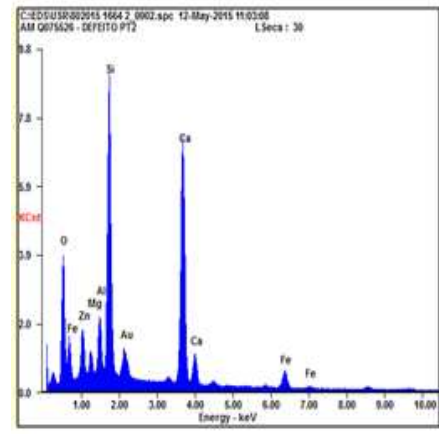

(c)

Figura 1 - Defeito esfoliação em aço UBC sendo (a) defeito no identificado no cliente, (b) micrografia optica revelando $\mathrm{Al}_{2} \mathrm{O}_{3}$ na região do defeito e (c) microscopia eletronica de varredura confirmando a presença de O, Fe, Zn, Mg, Al, Si e Ca [5].

De forma preventiva as placas cujo evento de desobstrução de veio é evidenciado, as mesmas recebem downgrade de qualidade minimizando o risco de aparecimento do defeito em produtos processados pelo cliente.

O presente trabalho apresenta o estudo bem como as ações realizadas para identificar e reduzir as ocorrências de obstrução dos veios na máquina de lingotamento contínuo no 2 . 


\section{MATERIAIS E MÉTODOS}

Com base nos resultados obtidos em 2013, iniciamos um estudo para identificar a ocorrência de obstrução e sua relação entre equipamentos, classificação de aço, turno e período.

Utilizando as ferramentas estatísticas foi levantando os dados históricos dos desvios de placas devido da desobstrução de veio ou unglogging, denominada internamente como "varada". Essa atividade operacional é realizada pelo operador líder sempre quando ocorre a restrição acentuada do fluxo de aço juntamente com o aumento a abertura da gaveta.

Analisando este indicador de varada, evidenciamos o aumento das ocorrências de obstrução dos veios atingindo valores superiores ao histórico obtido nos últimos anos.

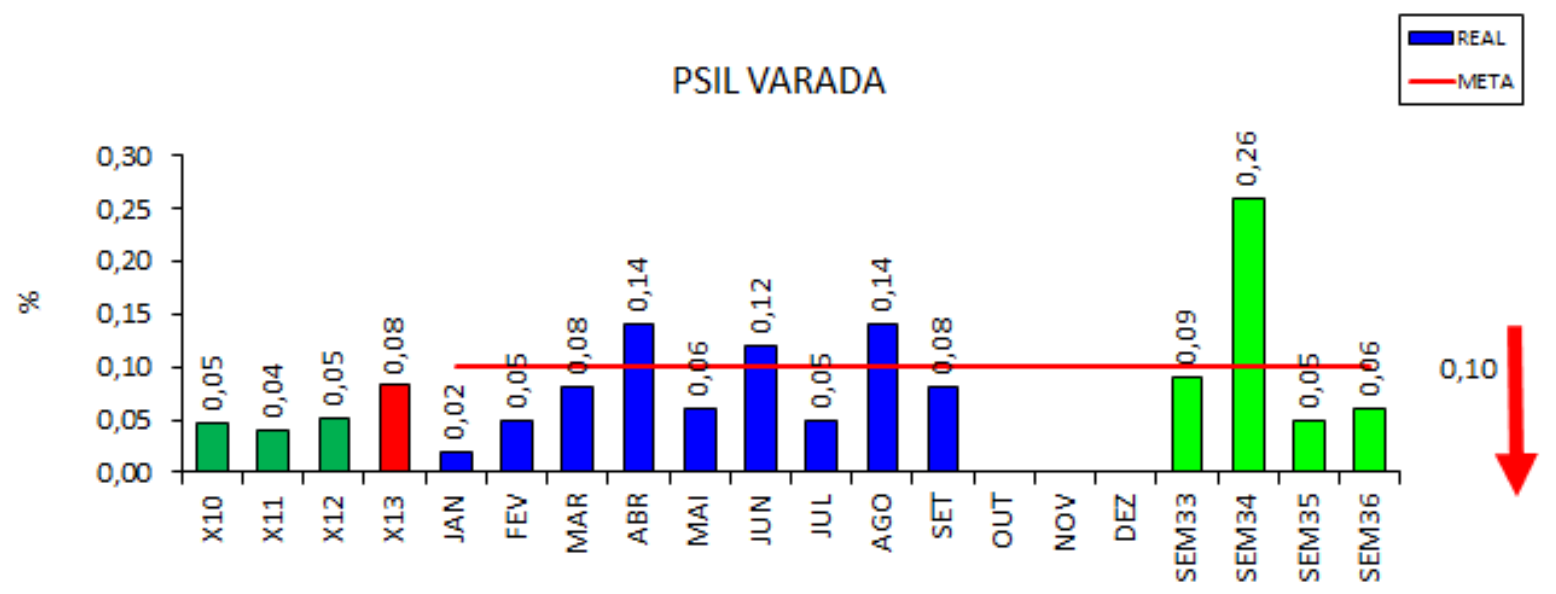

Figura 2 - Controle placas desviadas desobstrução de veio nas MCC 2,3 e 4.

Depurando os dados, foi evidenciado que o indicador da MCC2 figurava negativamente apresentando maior quantidade de varadas quando comparado com as máquinas de lingotamento continuo no 3 e 4 .

DESVIO DE PLACAS POR VARADAS - MCC 2

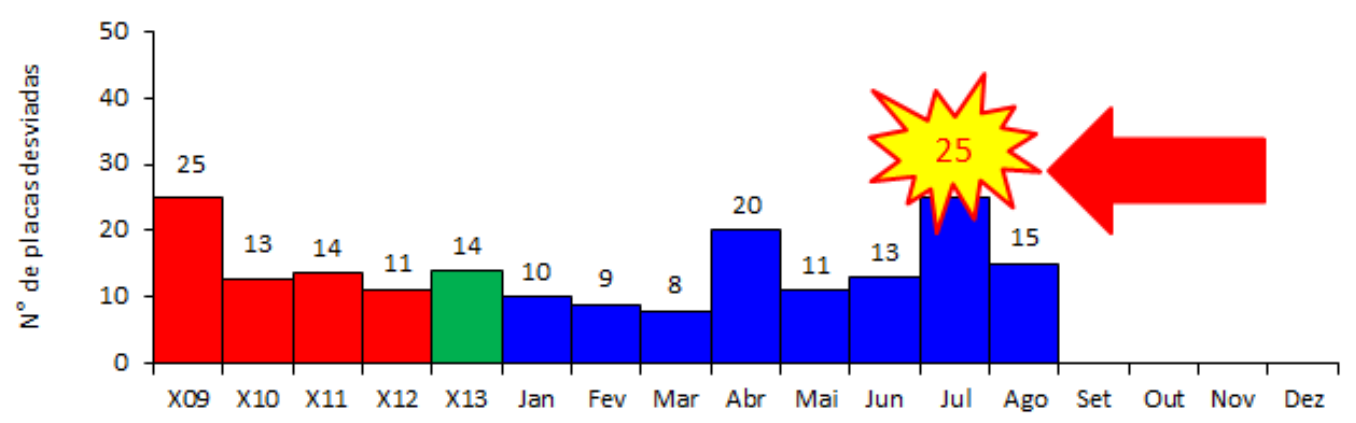

Figura 3 - Controle quantidade de placas desviadas por obstrução na MCC2. 
Evidenciamos em julho de 2013, este o veio C da MCC2 indicava pior resultado alcançando 20 ocorrências por mês.

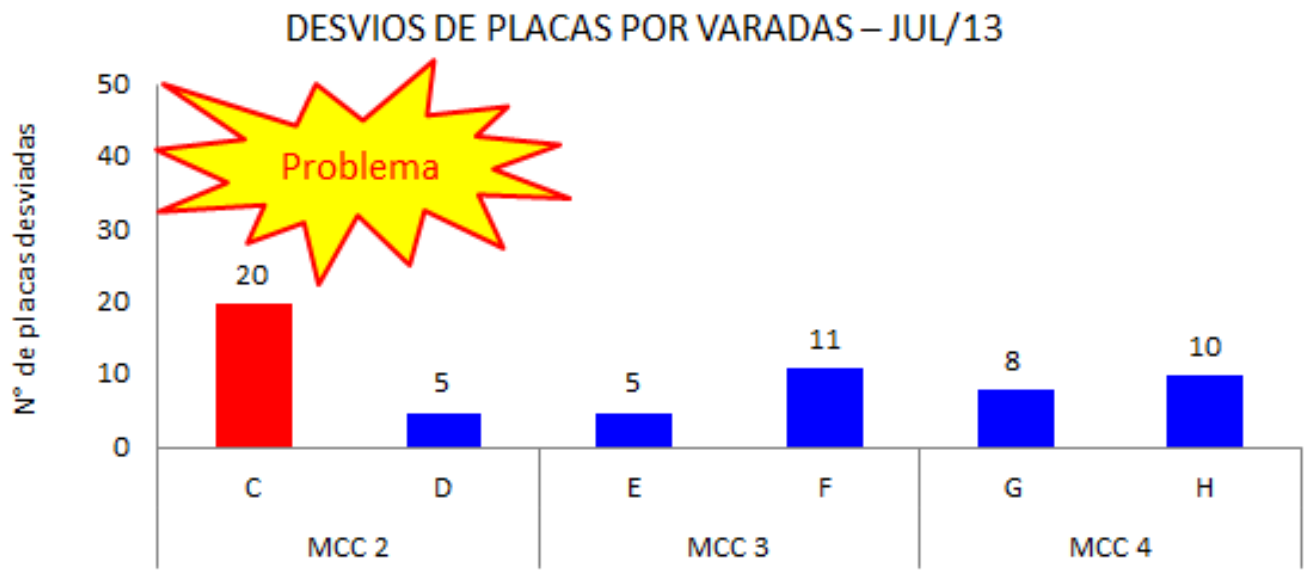

Figura 4 - Controle quantidade de placas desviadas por obstrução na MCC2 versus MCC 3 e 4.

Diante dos dados levantados, determinamos identificar e eliminar as causas dos desvios de placas devido à desobstrução dos veios na MCC2.

Conforme literatura, a obstrução química ocorre em duas etapas, sendo a primeira iniciada pela reação do alumínio dissolvido com os óxidos dos componentes refratários conforme equação abaixo.

$$
3 \mathrm{MgO}_{(\mathrm{l})}+2 \underline{\mathrm{Al}}=\mathrm{Al}_{2} \mathrm{O}_{3(\mathrm{~s})}+3 \underline{\mathrm{Mg}} \quad \Delta \mathrm{G}^{\circ}=67668-32,16 \mathrm{~T}(\mathrm{~J} / \mathrm{mol})[6]
$$

A segunda etapa é determinada pela deposição progressiva de alumina na parede da válvula superior e ou tubo submerso, reduzindo a área efetiva do fluxo de aço. A obstrução pode ser determinada através das cartas gráficas do processo, onde ocorre o aumento da abertura da gaveta à medida que a restrição do fluxo de aço ocorre.

Existem alguns pontos suscetíveis à formação do clogging, devido à interação aço, material refratário e ar. Durante o estudo realizado a deposição da alumina identificada nas ocorrências da MCC2 estava localizada na válvula superior e tubo submerso.

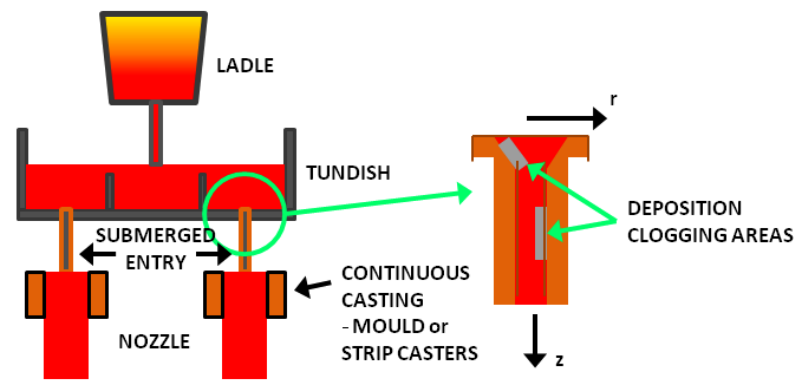

Figura 5 - Esquema dos principais pontos de deposição de alumina identificados na MCC2.[7] 
Diante do que foi analisado e evidenciado, construímos um gráfico de correlações auxiliando na detecção dos possíveis modos de falhas que contribuem com a ocorrência de obstrução.

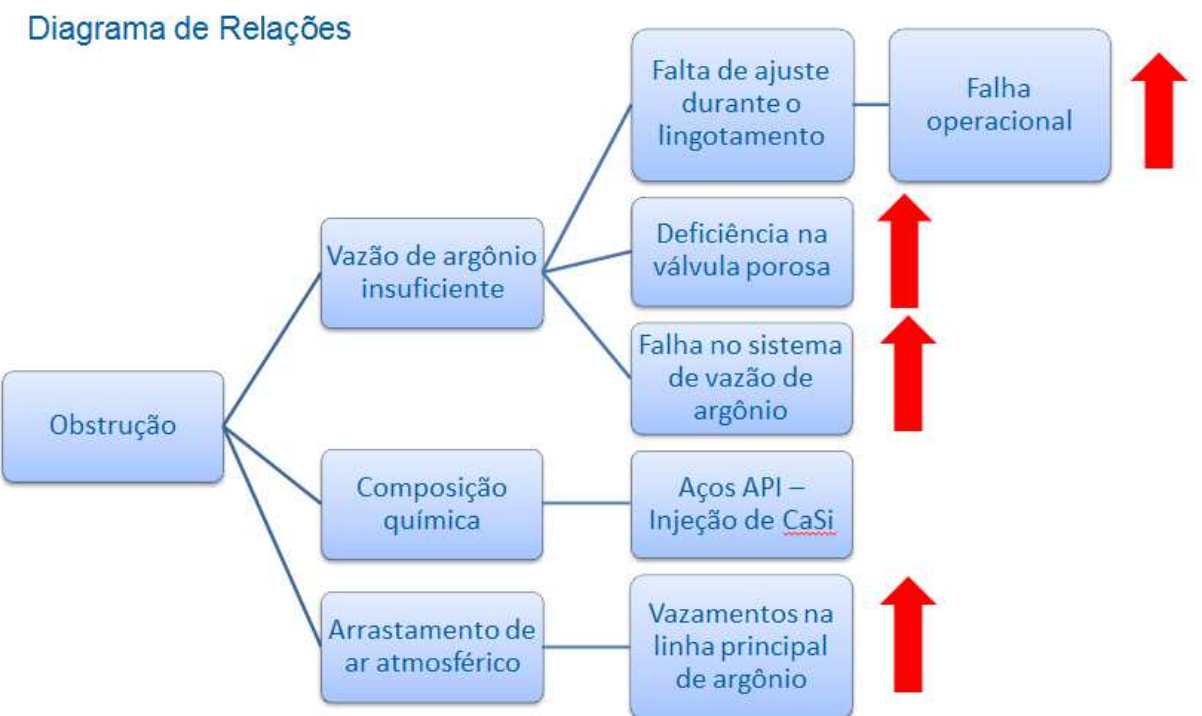

Figura 6 - Diagrama de correlações obstrução por deposição de alumina.

Devido à correlação da obstrução com a falha operacional, falha no sistema de vazão de argônio e deficiência na válvula porosa. Elaboramos um plano de ação para eliminar as causas e reduzir o índice de varada na MCC2.

\begin{tabular}{|c|c|c|c|c|c|c|c|c|}
\hline \multicolumn{9}{|c|}{ PLANO DE AÇÃO } \\
\hline \multirow{2}{*}{$\begin{array}{c}\text { Causa } \\
\text { Priorizada }\end{array}$} & \multirow{2}{*}{$\begin{array}{l}\text { Solução a ser } \\
\text { implementada }\end{array}$} & \multicolumn{7}{|c|}{$5 \mathrm{~W} 2 \mathrm{H}$} \\
\hline & & $\begin{array}{c}\text { What } \\
\text { (Atividade) }\end{array}$ & Who & When & Why & Where & How & $\begin{array}{l}\text { How } \\
\text { Much }\end{array}$ \\
\hline \multirow{4}{*}{\begin{tabular}{|c|} 
Baixo volume \\
de argônio na \\
válvula porosa \\
veios Ce D
\end{tabular}} & $\begin{array}{l}\text { Treinamento dos } \\
\text { operadores de veio }\end{array}$ & $\begin{array}{c}\text { Treinar operadores de } \\
\text { veio }\end{array}$ & GLA & Agosto-13 & $\begin{array}{c}\text { Evitar a obstrução } \\
\text { prematura dos } \\
\text { veios }\end{array}$ & $\operatorname{MCC} 2$ & \begin{tabular}{|} 
Padronizando \\
ajuste de \\
argônio \\
durante o \\
lingotamento
\end{tabular} & $\begin{array}{l}\text { Não há } \\
\text { custo }\end{array}$ \\
\hline & $\begin{array}{l}\text { Upgrade do painel de } \\
\text { controle de argônio } \\
\text { dos veios C e D }\end{array}$ & $\begin{array}{c}\text { Remover tubulação sem } \\
\text { utilização, limpar painele } \\
\text { instalarválvula de vazão } \\
\text { como redundância }\end{array}$ & GLA & Outubro-13 & $\begin{array}{c}\text { Garantir vazão de } \\
\text { argônio evitando } \\
\text { obstrução } \\
\text { prematura dos } \\
\text { veios }\end{array}$ & $\operatorname{MCC} 2$ & \begin{tabular}{|c|} 
Otimizar \\
ligações das \\
linhas de \\
argônio do \\
painel de \\
controle \\
\end{tabular} & $\begin{array}{l}\text { Não há } \\
\text { custo }\end{array}$ \\
\hline & $\begin{array}{c}\text { Acompanhamento } \\
\text { diário }\end{array}$ & $\begin{array}{c}\text { Analisar diariamente as } \\
\text { ocorrência de desvio por } \\
\text { obstrução }\end{array}$ & GLA & \begin{tabular}{|c} 
Novembro- \\
13
\end{tabular} & $\begin{array}{l}\text { Verificação da } \\
\text { eficácia }\end{array}$ & $\operatorname{MCC} 2$ & $\begin{array}{c}\text { Controles } \\
\text { específicos e } \\
\text { PDCA }\end{array}$ & $\begin{array}{l}\text { Não há } \\
\text { custo }\end{array}$ \\
\hline & Teste válvula superior & Verificar contrapressão & GLA & Janeiro-14 & $\begin{array}{c}\text { Garantir a vazão } \\
\text { preconizada no } \\
\text { projeto da válvula }\end{array}$ & $M C C 2,3 \in 4$ & $\begin{array}{l}\text { Utilização } \\
\text { padrão de } \\
\text { teste de } \\
\text { bancada }\end{array}$ & $\begin{array}{l}\text { Não há } \\
\text { custo }\end{array}$ \\
\hline
\end{tabular}

Figura 7 - Plano de ação, 5W2H. 


\section{RESULTADOS E DISCUSSÃO}

Após implementação das ações evidenciamos melhora significativa nas ocorrências de obstrução da MCC2. Em linhas gerais foram efetuas as seguintes atividades:

- Upgrade a estação de argônio veio D e C

- Treinamento operacional - controle e ajuste de argônio;

- Melhoria no projeto refratário válvula superior.

O upgrade da estação de argônio consistiu na mudança da configuração das válvulas controladoras de pressão, eliminado assim, possível erros de ajuste do argônio bem como possíveis vazamentos. A Figura 8 apresenta a configuração da estação de argônio após mudança da configuração.
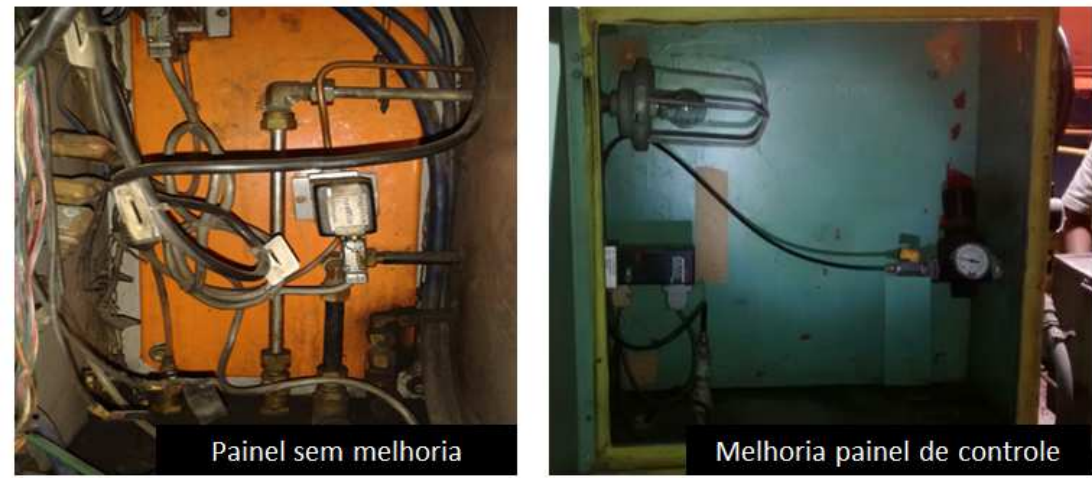

Figura 8 - Painel de controle argônio antes e depois da intervenção.

Foi realizado também treinamento operacional devido relação entre o ajuste de argônio e a obstrução. Durante as ocorrências de varada, foi evidenciado que o operador de veio não ajustava corretamente e de forma crescente as vazões de argônio superior e inferior contribuindo com a deposição da alumina na válvula superior. Após os treinamentos realizados com todas as equipes, evidenciamos melhora significativa do controle operacional conforme as cartas gráficas abaixo.

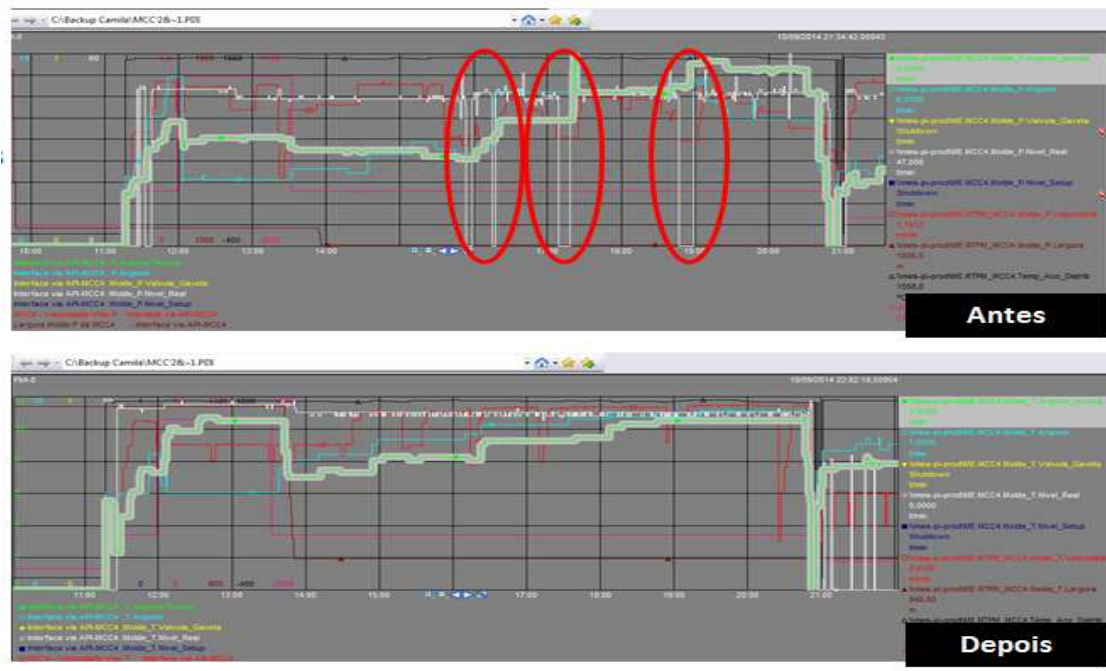

Figura 9 - Carta gráfica de controle do lingotamento contínuo aço BC.

E por ultimo executamos juntamente com o fornecedor, melhoria do projeto das válvulas superior. Durante o lingotamento identificamos que as válvulas apresentavam baixa vazão. Diante disso solicitamos adequação dos valores de 
pressão e porosidade contemplando-os nos limites de controle exigidos pelo processo. Preventivamente, 0 teste de bancada foi implantado possibilitando detectar as válvulas com anormalidades antes da montagem das mesmas. O teste consiste em verificar a contrapressão das câmaras superior e inferior mediante vazão de $60 \mathrm{Nl} / \mathrm{min}$. Logo é possível certificar o comportamento isobárico das válvulas.

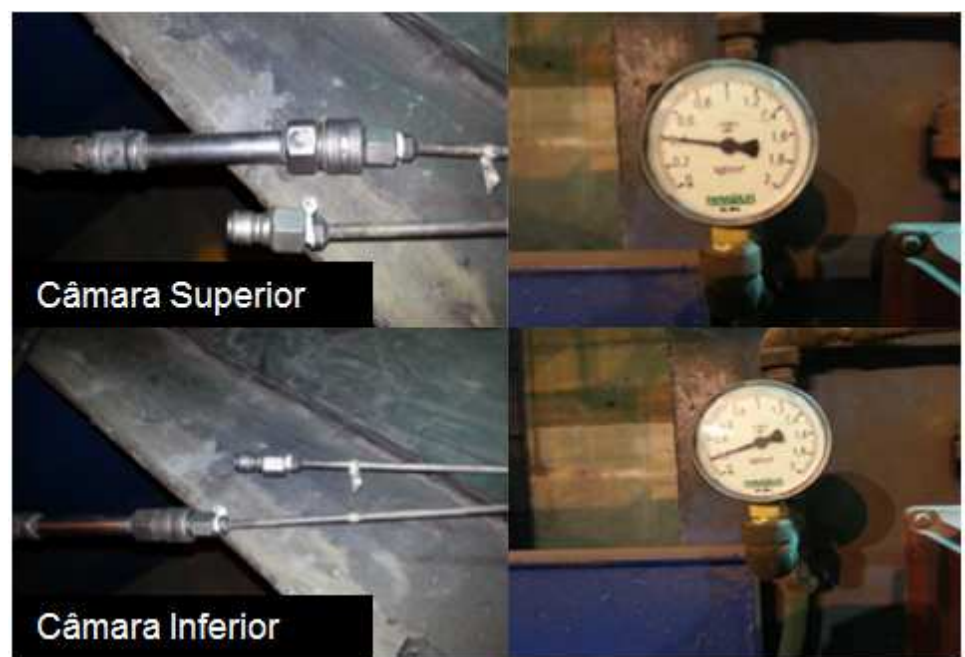

Figura 10 - Válvula superior produzidas com ajustes da porosidade do material refratário.

A implementação das ações acima permitiu uma redução significativa da obstrução na MCC2. Como se pode observada na Figura 11, os tubos que anteriormente já possuiam a deposição de alumina com 128 min, passaram a apresentar pouquíssimo material aderido mesmo após 535 min mantendo o diâmetro original do canal de fluxo de $70 \mathrm{~mm}$.

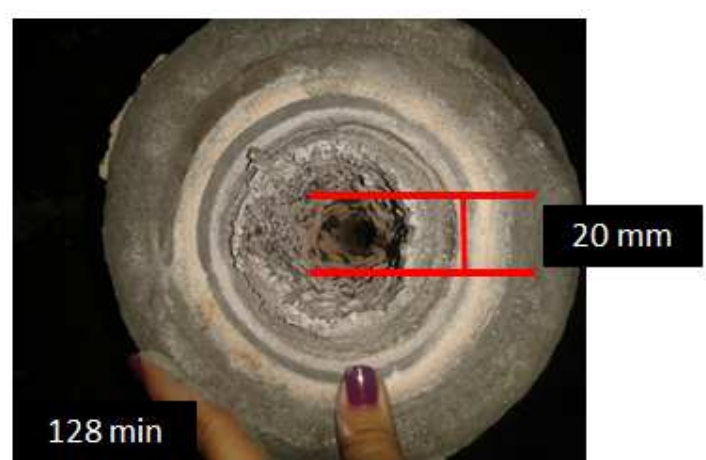

(a)

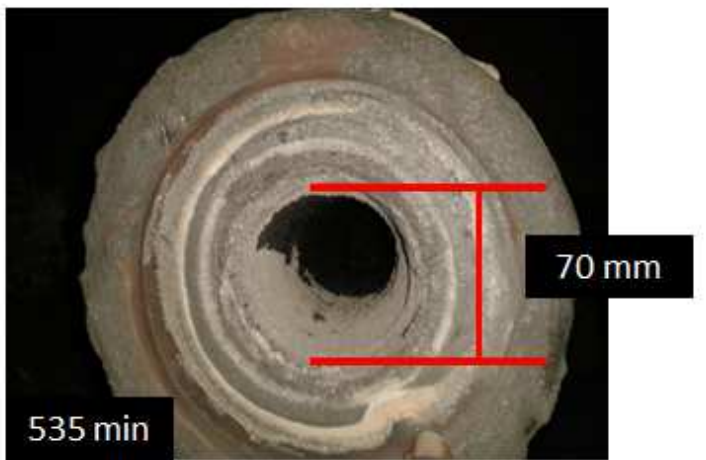

(b)

Figura 11 - Tubo submerso apresentando (a) obstrução prematura durante o lingotamento e (b) deposição de alumina sem restrição do fluxo de aço.

Tal redução na deposição de alumina no tubo submerso proporcionou uma redução no índice de varada nos veios $C$ e $D$, atingindo a melhor média mensal do equipamento nos últimos 5 anos, como pode ser observado na Figura 12. 
Desvio de placas por varadas - MCC 2

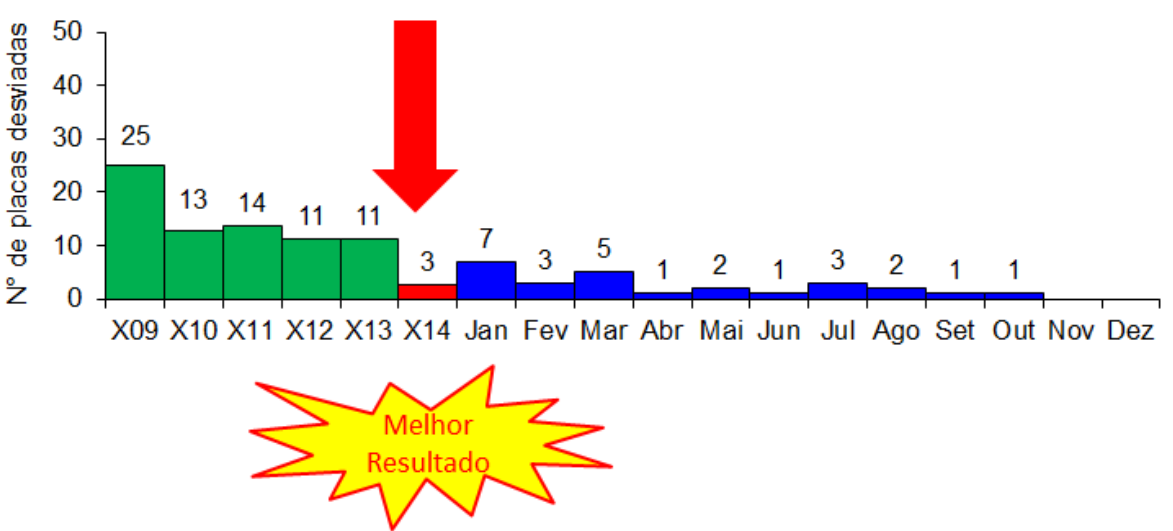

Figura 12 - Desvio de placas por varada após conclusão das ações.

Comparando os resultados obtidos em julho de 2014 com o período anterior onde evidenciamos anormalidade no processo da MCC2, observa-se a involução das ocorrências de varada nos veios $C$ e $D$ apresentando um desempenho superior aos outros equipamentos. Com o índice obtido foi possível determinar a MCC2 benchmarking do lingotamento contínuo da CSN.

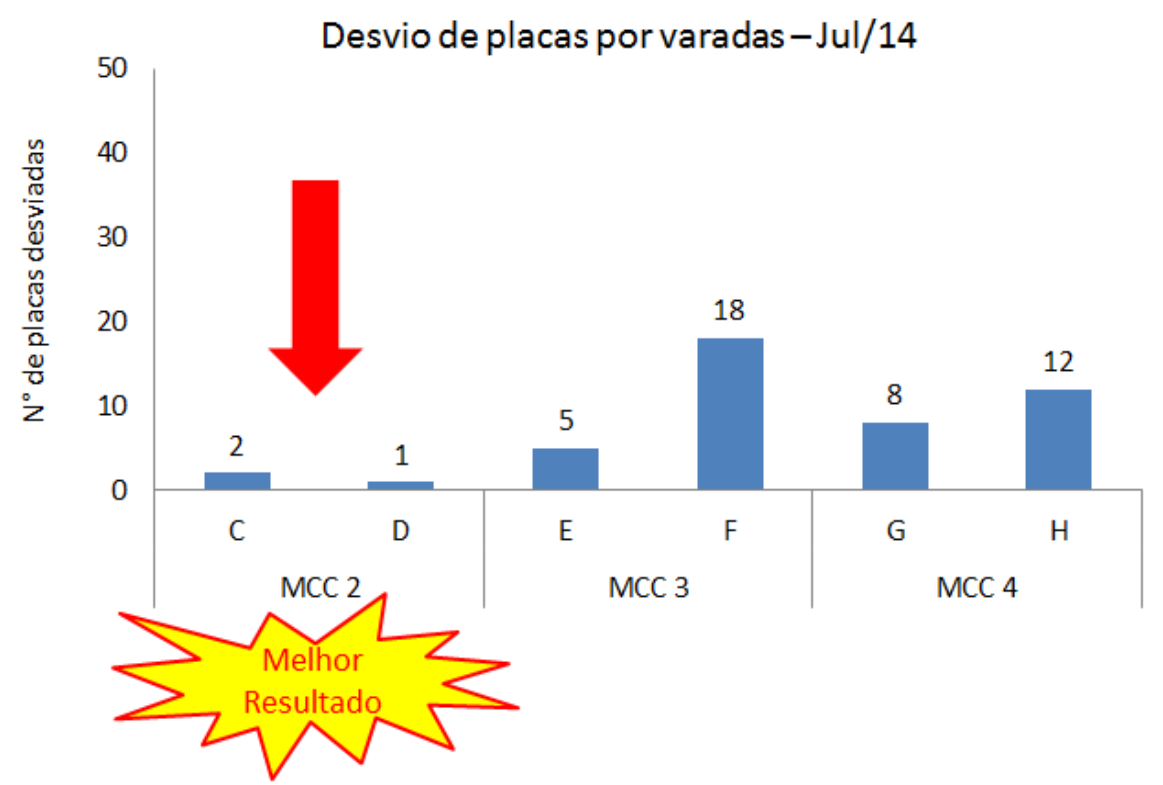

Figura 13 - Melhor resultado de desvio de placas na MCC2.

\section{CONCLUSÃO}

O presente trabalho possibilitou analisar e evidenciar as ocorrências de obstrução de veios durante o lingotamento na MCC2. Foi possível detectar que o veio C da MCC2 possuía o pior resultado dentre os outros equipamentos.

Foi também constatado que a deposição de alumina ocorria preferencialmente nas paredes do tubo submerso e válvula superior restringindo o fluxo de aço até provocar a interrupção do sequencial, de maneira prematura. Conforme a literatura foi possível certificar que a deposição de alumina teve origens químicas e não térmicas conforme se esperava. 
Foi constatada a correlação entre ajuste de argônio ineficiente com a ocorrência de obstrução consequentemente desvio de placas por varada. Os vazamentos na tubulação de argônio bem como a falha dos transistores digitais do painel eletrônico também contribuíram para o baixo desempenho operacional.

A variação entre as contrapressões da câmara superior e inferior das válvulas superior, identificadas nos testes de bancada, permitia a ineficiência da injeção de argônio potencializando a formação do clogging.

O reparo na estação de injeção de argônio bem como a eliminação dos vazamentos existentes nas tubulações possibilitou melhor controle e ajuste operação do gás inerte durante o sequencial.

O treinamento operacional possibilitou agregar mais perícia aos operadores de veio durante a atividade de controle do veio.

Juntamente com as atuações acima citadas, o ajuste do projeto da válvula superior permitiu a eliminação das causas que contribuíram para o aumento das ocorrências de obstrução bem como os desvios de placas na MCC2.

Conclui-se, portanto o presente trabalho atingiu de forma satisfatória o objetivo esperado reduzindo drasticamente as ocorrências de obstruções na MCC2 contribuindo com a redução dos custos, aumento da produtividade, segurança operacional e melhoria na qualidade interna das placas.

\section{Agradecimentos}

Os autores do trabalho agradecem a toda equipe de operação e suporte do Lingotamento Contínuo.

\section{REFERÊNCIAS}

1 RACKERS, K., and B.G. Thomas. Clogging in Continuous Casting Nozzles. 78th Steelmaking Conference Proceedings, Nashville, TN, April 2, 1995, Iron and Steel, Society, Warrendale, PA, Vol. 78, 1995, pp. 723-734.

2 NASCIMENTO, R.L., et alli. Apostila treinamento Staff - CSN, 2006, Volta Redonda, Rio de Janeiro.

3 MORAIS, A. Estudo fenomenológico do mecanismo de obstrução do fluxo de aço do distribuidor para o molde no início do lingotamento contínuo de placas, 2006. $169 \mathrm{f}$ Dissertação [Mestrado em Engenharia de Materiais]. Universidade Federal de Ouro Preto, Ouro Preto.

4 HAHNE, C. Otimização do processo de desoxidação do aço e tratamento de inclusões com cálcio para fundição no lingotamento continuo, 1998. 143 f. Dissertação [Mestrado em Engenharia de Materiais], UFMG, Belo Horizonte.

5 ZHANG, L., and and B.G. Thomas. INCLUSIONS IN CONTINUOUS CASTING OF STEEL. XXIV National Steelmaking Symposium, Morelia, Mich, Mexico, 26-28, Nov.2003, pp. 138-183.

6 SILVA, J.M.F. Melhoria da lingotabilidade do aço inoxidável AISI 409 na Arcelor Mital Inox, 2009. 74 f. Dissertação [Mestrado em Engenharia de Metalúrgica e Minas]. Universidade Federal de Minas Gerais, Belo Horizonte.

7 COLLA, V. New strategies for clogging prevention for improved productivity and steel quality. 2008 [acesso em 26 mar. 2015]. Disponível em: http://www.percro.org/node/759 